Neurosci Lett 31:41

2. Blass JP 1983 Inborn errors of pyruvate metabolism. In: Stanbury JB, Wyngaarden JB, Fredrickson DS, Goldstein JL, Brown MS (eds) The Metabolic Basis of Inherited Disease. McGraw-Hill Book Company, New York, pp 193-203

3. Blass JP, Cederbaum SD, Kark RAP 1977 Rapid diagnosis of pyruvate and ketoglutarate dehydrogenase deficiencies in platelet-enriched preparations from blood. Clin Chim Acta 75:21

4. Coude FX, Saudubray JM, Demangre F, Marsac C, Leroux JP 1978 Dichloroacetate as treatment for congenital lactic acidosis. N Engl J Med 299:1365

5. Crabb DW, Yount EA, Harris RA 1981 The metabolic effects of dichloroacetate. Metabolism 30:1024

6. Evans OB, Stacpoole PW 1982 Prolonged hypolactemia and increased total pyruvate dehydrogenase activity by dichloroacetate. Biochem Pharmacol 31:1295

7. Gutman I, Wahlgeld AW 1974 L-(+)-Lactate: determination with lactate dehydrogenase and NAD. In: Bergmeyer HU (ed) Methods of Enzymatic Analysis. Academic Press, New York, pp 1464-1468

8. Harris RA, Paxton R, Parker RA 1982 Activation of the branched-chain $\alpha$ ketoacid dehydrogenase complex by a broad specificity protein phosphatase. Biochem Biophys Res Commun 107:1497

9. Leiter AB, Weinberg M, Isohashi F, Utter MF 1978 Relationship between phosphorylation and activity of pyruvate dehydrogenase in rat liver mitochondria and the absence of such a relationship for pyruvate carboxylase. $J$

\section{Biol Chem 253:2716}

10. Lowry OH, Passonneau JV, Hasselberger FX, Schulz DW 1964 Effect of ischemia on known substrates and cofactors of the glucolytic pathway in brain. J Biol Chem 239:18

11. Maesaka H, Komiya K, Misugi K, Tada K 1976 Hyperalaninemia, hyperpyruvicemia and lactic acidosis due to pyruvate carboxylase deficiency of the liver: treatment with thiamine and lipoic acid. Eur J Pediatr 122:159

12. McKhann G, Francois B, Evrard P 1980 Long term use of low doses of dichloroacetate in a child with congenital lactic acidosis. Pediatr Res 14:167

13. Morgan DG, Routtenberg A 1982 Brain pyruvate dehydrogenase activity: regulation by phosphorylation-dephosphorylation. Brain Res 251:391

14. Robinson BH, Tayler J, Francois B, Beaudet AL, Peterson DF 1983 Lactic acidosis, neurological deterioration and compromised cellular pyruvate oxidation due to a defect in the reoxidation of cytoplasmically generated NADH. Eur J Pediatr 140:98

15. Stacpoole PW, Moore GW, Kornhauser DM 1978 Metabolic effects of dichloroacetate in patients with diabetes mellitus and hyperlipoproteinemia. N Engl J Med 298:526

16. Toshima K, Kuroda Y, Hashimoto T, Ito M, Watanabe Y, Miyao M, Ii K 1982 Enzymologic studies and therapy of Leigh's disease associated with pyruvate decarboxylase deficiency. Pediatr Res 16:430

17. Whitehouse S, Cooper RH, Randle PJ 1974 Mechanism of activation of pyruvate dehydrogenase by dichloroacetate and other halogenated carboxylic acids. Biochem J 141:761

\title{
The Onset of Breathing at Birth Stimulates Pulmonary Vascular Prostacyclin Synthesis
}

\author{
CHARLES W. LEFFLER, JACK R. HESSLER, AND ROBERT S. GREEN \\ Departments of Physiology and Biophysics [C.W.L., J.R.H., R.S.G.] and Pediatrics-Newborn Center [R.S.G.], \\ University of Tennessee Center for the Health Sciences, Memphis, Tennessee 38163
}

\section{Summary}

The purpose of the present study was to determine if pulmonary prostacyclin synthesis was stimulated by spontaneous onset of breathing by unanesthetized fetuses at birth. Cannulae were implanted and flow cuffs placed in fetal lambs and goats $(0.93$ term). Fetuses were delivered by cesarean section at 0.95 term and began breathing spontaneously. Prostacyclin in blood was determined by radioimmunoassay of its hydrolysis product, 6ketoprostaglandin $F_{1 \alpha}$ using methods that produced the same values in duplicate samples as did gas chromatography with electron capture detection. Fetal pulmonary prostacyclin production (left lung) [(left pulmonary venous concentration - pulmonary arterial concentration) $\times$ left pulmonary blood flow] was undetectable $\left[-1.7 \pm 1.0(\mathrm{SEM}) \mathrm{ng} \mathrm{PGI}_{2} \cdot \mathrm{kg}^{-1} \cdot \mathrm{min}^{-1}\right]$ and fetal pulmonary vascular resistance (left lung) high $(5.1 \pm 0.9 \mathrm{~mm}$ $\left.\mathrm{Hg} \cdot \mathrm{kg} \cdot \mathrm{min} \cdot \mathrm{ml}^{-1}\right)$. Pulmonary prostacyclin production increased to $30.1 \pm 12.3 \mathrm{ngPGI} \cdot \mathrm{kg}^{-1} \cdot \mathrm{min}^{-1}$ and pulmonary vascular resistance declined to $0.5 \pm 0.1 \mathrm{~mm} \mathrm{Hg} \cdot \mathrm{kg} \cdot \mathrm{min} \cdot \mathrm{ml}^{-1} 15 \mathrm{~min}$ after

Received November 4, 1983; accepted March 13, 1984.

Correspondence may be addressed to Dr. Charles W. Leffler, University of Tennessee Center for the Health Sciences, Department of Physiology and Biophysics, 894 Union Avenue (426 NA), Memphis, TN 38163.

This work was done during the tenure of an Established Investigatorship from the American Heart Association (C. W. L.) and with funds contributed in part by the Tennessee Affiliate. The research was supported in part by National Institutes of Health Grant HL22639, a grant-in-aid from the American Heart Association with funds contributed in part by the Tennessee Affiliate, a grant-in-aid from the Tennessee Lung Association, and Biomedical Research Support Grant from the University of Tennessee College of Medicine. birth. Pulmonary vascular resistance remained low even though pulmonary prostacyclin production fell $2-5 \mathrm{~h}$ after birth. These results, coupled with earlier studies using indomethacin to inhibit prostaglandin synthesis, support the hypothesis that pulmonary prostacyclin synthesis participates in the decline of pulmonary vascular resistance that accompanies the onset of ventilation at birth, but may be less important in maintenance of low pulmonary vascular resistance once reduced pulmonary vascular tone has been established.

\section{Abbreviations}

PG, prostaglandin

TX, thromboxane

GC-ECD, gas chromatography-electron capture detection RIA, radioimmunoassay

Reduction of pulmonary vascular resistance with the onset of breathing at birth allows right ventricular blood to pass through the pulmonary circulation and, thus, pulmonary gas exchange to occur. In anesthetized, exteriorized, fetal lamb preparations, Cassin et al. (4) found that rhythmic ventilation with a gas, increasing $\mathrm{PO}_{2}$, and decreasing $\mathrm{PCO}_{2}$ (increasing $\mathrm{pH}$ ) all contribute to the pulmonary vasodilation. In a similar preparation, ventilation-induced pulmonary vasodilation at birth consisted of a rapid decline in the first $30 \mathrm{sec}$ followed by a slower, more prolonged vasodilation over the first $20 \mathrm{~min}$ or more (13). 
Although the mechanisms of pulmonary vasodilation at birth have not been elucidated, evidence for a role of prostacyclin is beginning to accumulate. This evidence, gathered using anesthetized preparations and mechanical ventilation, includes 1) removal of a dilator influence from the neonatal pulmonary circulation by prostaglandin cyclooxygenase inhibition $(28), 2$ ) abolition of the slow decline phase of pulmonary vasodilation by indomethacin pretreatment of fetal goats (13), 3) net production of prostacyclin-like material following ventilation of fetal lungs perfused with blood $(15), 4)$ stimulation of prostacyclin synthesis by mechanical ventilation of fetal lungs perfused with Krebs solution (17), and 5) pulmonary vasodilation of fetal lamb lungs by infusion of authentic prostacyclin $(5,10,14)$.

The possibilities that surgical trauma exaggerated the prostacyclin response and that mechanical positive pressure ventilation is required for stimulation of prostacyclin synthesis could not be excluded when the experimental designs of the previous experiments were employed. Whether induction of pulmonary vascular prostacyclin synthesis is a component of normal perinatal transitions was not known. Therefore, the present investigation was undertaken to monitor pulmonary prostacyclin production prior to and following the spontaneous onset of ventilation at birth.

\section{MATERIALS AND METHODS}

Instrumentation of Fetuses. The mothers of six fetuses (three lambs and three kids) ( 135 days gestation; average term is 148150 days in both species) were anesthetized with thiamylal (22 $\mathrm{mg} / \mathrm{kg}$ ) and maintained on ethrane $(2-4 \%)$ and nitrous oxide $(50 \%)$. Utilizing strict aseptic procedure, the uterus was exposed through a midline incision. A left thoracotomy was performed on the fetus through a small incision made in the uterus above the left side of the fetal thorax. Tridodecylmethyl ammonium chloride and heparin complex-treated (Polysciences, Inc., Warrington, PA), graphite-coated (Acheson Colloid Co., Port Huron, MI), microline (Thermoplastic, Scientifics, Inc., Warren, NJ) cannulae (27) were inserted approximately $2 \mathrm{~mm}$ into the right pulmonary artery via the main trunk and into the descending aorta through punctures and secured with pursestring sutures. A third cannulae was inserted through the left atrial appendage and advanced approximately $1 \mathrm{~cm}$ into the left lower pulmonary vein. The position of the catheter was confirmed at autopsy. If the catheter was less than $5 \mathrm{~mm}$ into the vein, no data from the animal were used. The catheters selected were always less than half the diameter of the vessels in which their tips were placed to prevent obstruction of blood flow through the vessels. An electromagnetic flow cuff was placed around the left pulmonary artery [Carolina Medical Electronics, Inc. (King, NC) flowmeter and cuffs]. The fetal chest, amnion, and uterus were closed and catheters led, subdermally, to behind the maternal left shoulder and exteriorized. The flow probe lead was exteriorized laterally. Prophylactic gentamicin was administered to the mother $(5 \mathrm{mg}$. $\mathrm{kg}^{-1} \cdot$ day, iv), the baby $\left(5 \mathrm{mg} \cdot \mathrm{kg}^{-1} \cdot \mathrm{day}^{-1}\right.$, intra-arterially), and into the amnion ( $50 \mathrm{mg}$ during surgery).

Description of Experiment. Four days following surgery, the fetuses [3.4 \pm 0.3 (SEM) $\mathrm{kg}$ ] were delivered by cesarean section under maternal spinal anesthesia and light ethrane by mask. The umbilical cord was tied and cut and the newborns were allowed to begin breathing spontaneously. They were dried with towels and a hair dryer. Approximately $15 \mathrm{~min}$ after birth, newborns were immobilized in a cloth sling that did not interfere with respiratory movements. They were kept warm with an infrared lamp.

Fetal pulmonary arterial pressure, aortic pressure, and left pulmonary blood flow were monitored continuously from before maternal spinal anesthesia to 2-5 h following birth. Blood samples for prostacyclin determination were drawn from the pulmonary artery and left lower pulmonary vein prior to delivery and $15 \mathrm{~min}, 60 \mathrm{~min}$, and several times between 2 and $5 \mathrm{~h}$ following birth. Each blood sample consisted of $2 \mathrm{ml}$ of blood drawn into a heparinized plastic syringe containing $15 \mathrm{mg}$ meclofenamate. The blood was injected immediately into $10 \mathrm{ml}$ of $2^{\circ} \mathrm{C}$ saline in order to reduce the temperature rapidly and, thereby, decrease extracorporeal prostanoid generation and metabolism. The formed elements were removed by centrifugation $\left(34,000 \times g\right.$ for $20 \mathrm{~min}$ at $\left.2^{\circ} \mathrm{C}\right)$, and the supernatant (plasma + saline) was drawn off and stored at $-60^{\circ} \mathrm{C}$ for later analysis. Descending aorta samples $(0.5 \mathrm{ml})$ for blood gas and $\mathrm{pH}$ determinations were drawn into heparinized syringes before birth, at $15 \mathrm{~min}$ and $60 \mathrm{~min}$ after birth, and periodically thereafter.

At the conclusion of experimentation, neonates were killed with euthanasia solution (T-61) and autopsies were performed to ensure the lungs were well aerated without gross evidence of pathology and to confirm catheter placements.

Analytical Methods. Prostacyclin determination. The blood prostacylin concentration was determined by radioimmunoassy of its stable hydrolysis product, 6-keto- $\mathrm{PGF}_{1 \alpha}$, following chromatographic extraction (18). The samples were allowed to melt and were acidified to $\mathrm{pH} 3$ with formic acid. They were passed through octadecylsilyl cartridges (Sep-Pak, Waters Associates, Inc., Milford, MA) that had been washed and wetted previously with $30 \mathrm{ml}$ acetone, $30 \mathrm{ml}$ hexane, $60 \mathrm{ml}$ methanol, and $60 \mathrm{ml}$ water. The Sep-Pak containing the sample was washed with 20 $\mathrm{ml}$ water and $20 \mathrm{ml}$ petroleumether, both of which were discarded. The prostanoids were eluted with $10 \mathrm{ml}$ ethyl acetate (24). Fifteen $\mathrm{ml}$ of toluene were added to the $10 \mathrm{ml}$ ethyl acetate, and the mixture was passed through a silica gel column [Adsorbosil (Applied Science Division of Milton Roy Co. through Anspec, Inc., Ann Arbor, MI), $8 \mathrm{~cm} \times 5 \mathrm{~mm}$ ]. Prostanoids on the column were washed with $25 \mathrm{ml}$ of 60:40 (by volume) toluene:ethyl acetate (discarded) and were eluted with $15 \mathrm{ml}$ 60:40:5:1 toluene:ethyl acetate:methanol:formic acid. The eluants were evaporated under vacuum and the invisible residues were transferred to polypropylene tubes in $3 \times 500 \mu$ l methyl formate. The methyl formate was evaporated under nitrogen at $20^{\circ} \mathrm{C}$. Two samples containing 600 pg 6-keto-PGF $F_{1 \alpha}$ (Upjohn Co., Kalamazoo, MI) in charcoal-treated sheep plasma, two blank samples (charcoal-treated sheep plasma), and two samples containing ${ }^{3} \mathrm{H}-6-$ keto- PGF $_{1 \alpha}$ (New England Nuclear, Boston, MA) were processed similarly with each set of fetal samples. Recovery of ${ }^{3} \mathrm{H}-6$-keto- $\mathrm{PGF}_{1 \alpha}$ from plasma through the entire preparatory precedure was $87 \pm 3 \%$.

Radioimmunoassayable 6-keto- $\mathrm{PGF}_{1 \alpha}$ was determined using antiserum purchased from Seragen, Inc. (Boston, MA), raised in rabbits immunized with 6-keto-PGF ${ }_{1 \alpha}$ conjugated to bovine serum albumin. The cross-reactivity at $50 \% B / B_{0}$ of the 6-keto$\mathrm{PGF}_{1 \alpha}$ antibodies with other examined prostanoids was: to $\mathrm{PGF}_{2 \alpha}$ $=5 \%$; to $\mathrm{PGE}_{2}=2 \%$; to $\mathrm{PGD}_{2}, \mathrm{TXB}_{2}$, and $\mathrm{PGA}_{2}$, and $\mathrm{PGA}_{2}<$ $0.2 \%$. Extracted samples were assayed at three dilutions. The assays were performed in gelatin-Tris buffer using ${ }^{3} \mathrm{H}-6$-keto$\mathrm{PGF}_{1 \alpha}$. Following 24-h incubation at $4^{\circ} \mathrm{C}$, the free fraction was separated from the fraction bound to antibody by precipitating the rabbit antibodies with anti-rabbit $\gamma$-globulin (Antibodies, Inc., Davis, $\mathrm{CA}$ ) and $60 \%$ saturated $\left(\mathrm{NH}_{4}\right)_{2} \mathrm{SO}_{4}$. Data were handled by computer, with determination of second order regression slope and intercept of free tracer over tracer bound to antibody against unlabeled 6-keto-PGF I $_{1 \alpha}$ by the method of least squares. Provided the slope of the sample dilution curve was not different from the standard curve, the quantity of 6 -keto-PGF - $_{1 \alpha}$ in the plasma of the blood sample was determined and expressed in $\mathrm{pg} / \mathrm{ml}$ of blood. Following extraction, the mean and standard error for the charcoal-treated plasma containing $600 \mathrm{pg}$ 6-keto$\mathrm{PGF}_{1 \alpha}$ was $599 \pm 53 \mathrm{pg}$. Following extraction, the charcoaltreated plasma without added prostaglandin contained $40 \pm 4$ pg "6-keto-PGF ${ }_{1 \alpha}$." In order to correlate the values obtained using these methods with those obtained via an independent method, nine samples were drawn from three newborn goats acutely prepared under chloralose anesthesia and the prostanoid profile and concentration of each prostanoid i 0.9 of each sample were determined using GC-ECD (16) while the concentration of 
6-keto-PGF - $_{1 \alpha}$ in the other 0.1 of the sample was determined by RIA. Liquid chromatographic preparation was identical as described above. The 6-keto-PGF - $_{1 \alpha}$ concentrations obtained by the two methods were virtually identical (GC-ECD: $638 \pm 109$ pg 6keto-PGF ${ }_{1 \alpha} / \mathrm{ml}$; RIA: $626 \pm 43 \mathrm{pg} 6$-keto-PGF $\left.{ }_{1 \alpha} / \mathrm{ml}\right)$ and not different statistically ( $t$ test on paired samples). In these nine samples, the concentration of 6 -keto- $\mathrm{PGF}_{1 \alpha}$ was more than 5 times that of $\mathrm{PGE}_{2}, \mathrm{PGD}_{2}, \mathrm{TXB}_{2}$ or 15-keto-13,14-dihydro- $\mathrm{PGE}_{2}$ (GC-ECD).

Calculations. Pulmonary prostacyclin production (left) per kg of newborn was defined as (left pulmonary venous prostacyclin concentration - pulmonary arterial prostacyclin concentration) $\times$ left pulmonary blood flow per $\mathrm{kg}$ of newborn. Pulmonary vascular resistance (left) was defined as pulmonary arterial pressure divided by weight (whole animal) specific left pulmonary blood flow. Fetal pulmonary venous pressure was indistinguishable from zero but could not be measured accurately because the exact level of the left atrium could not be determined. After birth, alveolar pressure at end expiration would be zero, intrapulmonary pressure would be less than atmospheric due to elastic recoil, and pulmonary venous pressure was less than $5 \mathrm{~mm} \mathrm{Hg}$. Therefore, we believe the best estimate of outflow pressure is zero and assume the pressure drop for calculating pulmonary vascular resistance to be equivalent to pulmonary arterial pressure.

Statistical Analysis. Pulmonary prostacyclin production before birth and that at 15,60, and 120-300 min after birth were compared using analysis of variance followed by Bonferoni $t$ tests to isolate differences between groups in analysis of variance. Pulmonary arterial and pulmonary venous prostacyclin concentrations of fetal animals were compared with concentrations at 15 min after birth using the paired $t$ test $(2,8)$.

\section{RESULTS}

The only difference observed in measured variables between sheep and goats was that calculated fetal pulmonary vascular resistance appeared to be about $50 \%$ higher in kids than in lambs. Since no differences were observed between species in prostacyclin production or cardiovascular alterations at birth, data from lambs and kids were combined.

Fetal pulmonary arterial blood gases and $\mathrm{pH}$ immediately prior to removal of the fetus from the uterus and clamping of the umbilical cord were: $\mathrm{pH}=7.34 \pm 0.03, \mathrm{Po}_{2}=17 \pm 1 \mathrm{~mm}$ $\mathrm{Hg}, \mathrm{PCO}_{2}=48 \pm 2 \mathrm{~mm} \mathrm{Hg}$. Aortic values from spontaneously ventilating newborns at $15 \mathrm{~min}, 1 \mathrm{~h}$ and $3 \mathrm{~h}$ after birth were: at $15 \mathrm{~min} \mathrm{pH}=7.16 \pm 0.01, \mathrm{PO}_{2}=42 \pm 9 \mathrm{~mm} \mathrm{Hg}, \mathrm{PCO}_{2}=65 \pm$ $12 \mathrm{~mm} \mathrm{Hg}$; at $1 \mathrm{~h}, \mathrm{pH}=7.22 \pm 0.06, \mathrm{PO}_{2}=48 \pm 7 \mathrm{~mm} \mathrm{Hg}$, $\mathrm{PCO}_{2}=47 \pm 9 \mathrm{~mm} \mathrm{Hg}$; and at $3 \mathrm{~h}, \mathrm{pH}=7.29 \pm 0.04, \mathrm{PO}_{2}=48$ $\pm 9 \mathrm{~mm} \mathrm{Hg}, \mathrm{PCO}_{2}=45 \pm 5 \mathrm{~mm} \mathrm{Hg}$, respectively.

The pulmonary arterial pressures, weight specific left pulmonary arterial blood flows, calculated pulmonary vascular resistances and systemic arterial pressures prior to and following birth are shown in Figure 1. Before birth, pulmonary arterial pressure and systemic arterial pressure were indistinguishable $(61 \pm 6 \mathrm{~mm}$ $\mathrm{Hg}$ ) and fetal left pulmonary arterial blood flow was low (12 \pm $\left.5 \mathrm{ml} \cdot \mathrm{min}^{-1} \cdot \mathrm{kg}^{-1}\right)$. Thus, calculated pulmonary vascular resistance was high $\left(5.1 \pm 0.9 \mathrm{~mm} \mathrm{Hg} \cdot \mathrm{kg} \cdot \mathrm{min} \cdot \mathrm{ml}^{-1}\right)$. With the onset of breathing at birth, pulmonary arterial blood flow increased progressively as pulmonary vascular resistance declined over the first $15 \mathrm{~min}$ of ventilation and pulmonary arterial pressure (58 $\pm 2 \mathrm{~mm} \mathrm{Hg}$ ) became less than systemic arterial pressure (64 \pm 3 $\mathrm{mm} \mathrm{Hg}$ ). The pulmonary vasodilation at birth occurred rapidly during the first $30 \mathrm{sec}$ of breathing and proceeded more slowly over the next approximately 15 to $20 \mathrm{~min}$. The fast decline in pulmonary vascular resistance during the first $30 \mathrm{sec}$ of ventilation is not evident in Figure 1 due to variability of duration between delivery and onset of effective ventilation. Within 15 min, effective ventilation, low pulmonary vascular resistance, and high pulmonary blood flow were established uniformly.

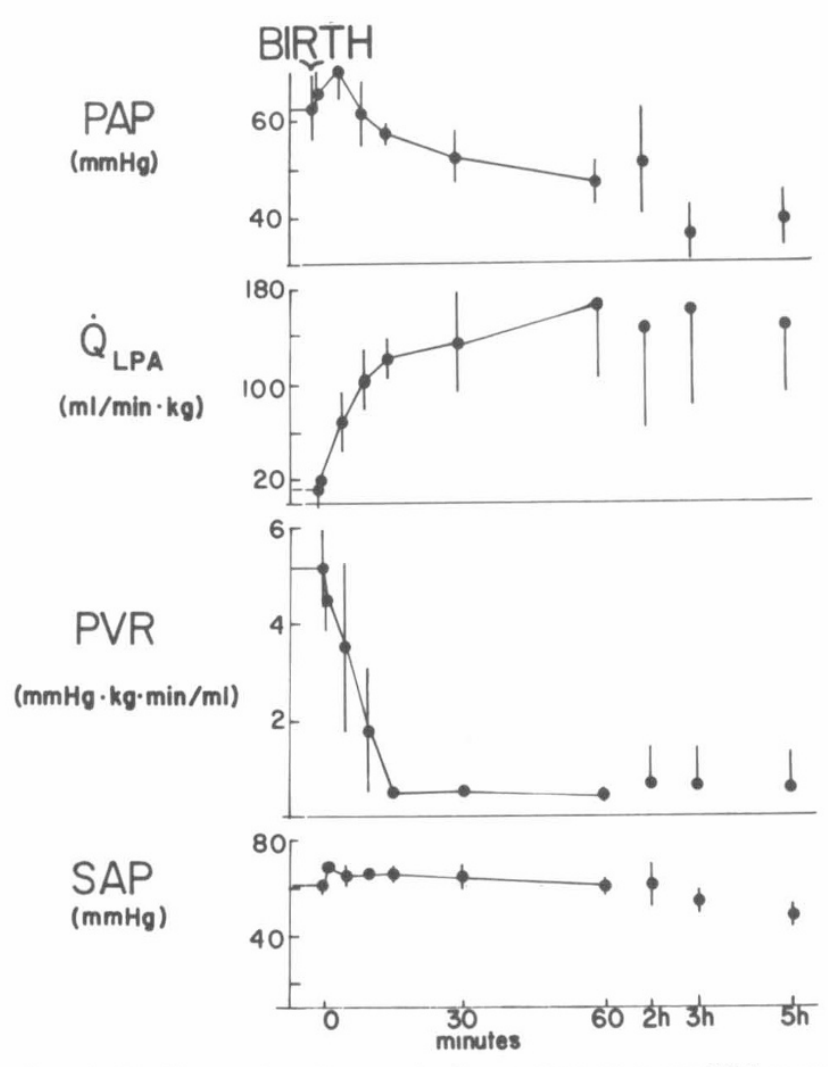

Fig. 1. Cardiovascular changes during spontaneous establishment of pulmonary gas exchange at birth in near term fetal lambs and goats. $P A P$, mean pulmonary arterial pressure; $Q_{L P A}$, weight specific (whole animal) left pulmonary arterial blood flow; $P V R$, calculated, weight specific, left pulmonary vascular resistance $\left(P A P / Q_{L P A}\right)$; and $S A P$, mean systemic arterial pressure (descending aorta). (Means \pm SEM.)

Table 1. Prostacyclin concentrations ( \pm SEM) in the pulmonary arteries and left lower pulmonary veins of fetal and newborn lambs and kids

\begin{tabular}{lllll}
\hline & \multicolumn{4}{c}{$\mathrm{PGI}_{2}$ concentration $(\mathrm{pg} / \mathrm{ml}$ of blood) } \\
\cline { 2 - 5 } & Fetal & \multicolumn{3}{c}{ Newborn (min after birth) } \\
\cline { 2 - 5 } & & 15 & 60 & $120-300$ \\
\hline Pulmonary artery & $447 \pm 117$ & $400 \pm 42$ & $438 \pm 90$ & $384 \pm 76$ \\
Pulmonary vein & $309 \pm 67$ & $645 \pm 94^{*}$ & $596 \pm 135$ & $443 \pm 51$ \\
\hline
\end{tabular}

${ }^{*} \mathrm{p}<0.05$, compared to fetal.

Table 1 shows pulmonary arterial and pulmonary venous prostacyclin concentrations prior to birth and 15, 60, and 120 $300 \mathrm{~min}$ after birth. Pulmonary arterial prostacyclin concentration did not change significantly during transition from fetus to newborn. In the fetus, there appeared to be removal and/or metabolism of prostacyclin during passage of blood through the pulmonary circulation since in five of six fetuses pulmonary arterial prostacyclin was greater then pulmonary venous. However, there was no significant difference between the fetal pulmonary arterial and pulmonary venous prostacyclin concentrations. Conversely, pulmonary venous prostacyclin concentration $15 \mathrm{~min}$ after birth was more than double the fetal concentration. Therefore, the lungs were producing prostacyclin $15 \mathrm{~min}$ after the spontaneous onset of ventilation at birth.

Figure 2 shows the left pulmonary vascular resistance and left pulmonary vascular prostacyclin production from the fetal state to $5 \mathrm{~h}$ after birth. Prior to birth, pulmonary synthesis of prostacyclin was not detectable because the lungs tended to remove more prostacyclin than they produced $\left(-1.7 \pm 1.1 \mathrm{ng} \cdot \mathrm{kg}^{-1}\right.$. $\left.\min ^{-1}\right)$. In contrast, $15 \mathrm{~min}$ after birth, there was considerable pulmonary prostacyclin production $\left(30.1 \pm 12.3 \mathrm{ng} \cdot \mathrm{kg}^{-1} \cdot \mathrm{min}^{-1}\right)$ 


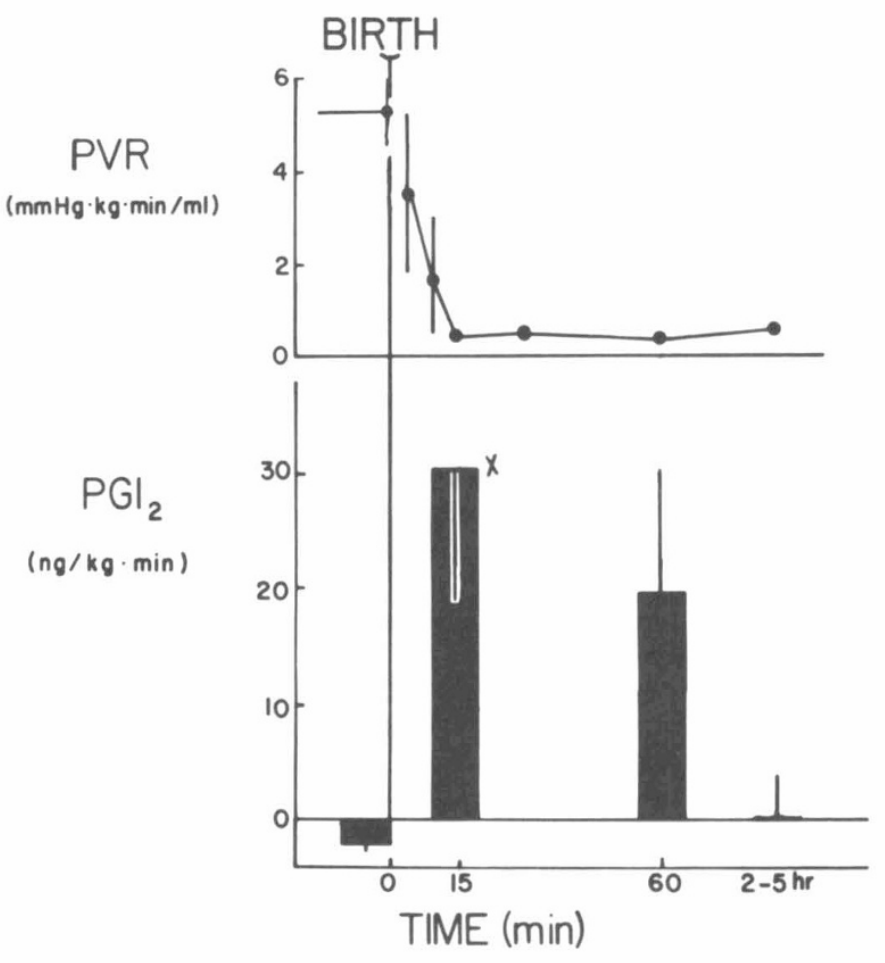

$X_{\text {greater than fotal }}(P<0.05)$

Fig. 2. Weight specific (whole animal), left pulmonary vascular resistances $(P V R)$ and weight specific, net, left pulmonary prostacyclin production $\left(\mathrm{PGI}_{2}\right)$ prior to, during, and following spontaneous establishment of pulmonary gas exchange at birth by lambs and kids. (Means \pm SEM.)

coincident with a decline in pulmonary vascular resistance from the fetal $5.1 \pm 0.9$ to the newborn $0.5 \pm 0.1 \mathrm{~mm} \mathrm{Hg} \cdot \mathrm{kg} \cdot \mathrm{min}$. $\mathrm{ml}^{-1}$. Pulmonary prostacyclin production then decreased to low levels by several hours following birth.

\section{DISCUSSION}

Current evidence indicates that prostacyclin is involved in perinatal pulmonary events in lambs and kids. The predominant prostanoid produced by perinatal lamb and goat lungs is prostacyclin $(15,17)$. Even though, prior to ventilation, prostacyclin synthesis is high in Krebs perfused fetal lungs, mechanical ventilation further increases prostacyclin synthesis (17). Similarly, mechanical ventilation of blood perfused lungs of exteriorized fetuses increases the net pulmonary production of prostacyclinlike material (15). The present study indicates that pulmonary prostacyclin production is stimulated greatly by the spontaneous onset of ventilation at birth and, therefore, appears to be a natural component of perinatal transition. The net pulmonary prostacyclin production $15 \mathrm{~min}$ following spontaneous onset of ventilation at birth $\left(30 \mathrm{ng} \cdot \mathrm{kg}^{-1} \cdot \mathrm{min}^{-1}\right)$ is similar to the production of prostacyclin-like material produced by blood perfused fetal lamb and goat lungs following $15 \mathrm{~min}$ of mechanical ventilation (55 $\left.\mathrm{ng} \cdot \mathrm{kg}^{-1} \cdot \mathrm{min}^{-1}\right)(15)$, although the plasma concentration of prostacyclin-like material in the exteriorized, anesthetized, surgically stimulated, fetal model was much higher than in the present investigation.

Prostacyclin is a potent vasodilator in the fetal lung $(5,10$, 14). Elevated intrapulmonary synthesis may result in high tissue levels of this prostanoid which could contribute to the pulmonary vasodilation at the onset of ventilation and, thus, perinatal circulatory transition. Pulmonary $\mathrm{PGI}^{2}$ production is greatest during the period of progressive pulmonary vasodilation. Further evidence of a cause-effect relationship derives from the effect of treatment of the fetus with indomethacin upon the subsequent, ventilation-induced, pulmonary vasodilation. In experiments using an exteriorized, anesthetized fetal goat model, the slow component of pulmonary vasodilation that normally proceeds through the first $20 \mathrm{~min}$ or more of ventilation was absent following inhibition of prostaglandin cyclooxygenase (13). Similarly, chronic treatment of ewes with indomethacin greatly attenuated pulmonary vasodilation by their fetuses at delivery (3).

Noticeably, although high pulmonary prostacyclin production accompanies pulmonary vasodilation at birth, this production is transient; yet postventilation low pulmonary vascular resistance is maintained. One possible hypothesis, although purely speculative, is that transient release of vasodilator substances in the pulmonary circulation with the onset of ventilation could, by allowing pulmonary blood flow to increase and/or by reducing pressure in intrapulmonary vessels, release a reflex or locally mediated vasoconstriction. Continued presence of the vasodilator might not be necessary to maintain low pulmonary vascular tone once the neonatal intrapulmonary conditions of high $\mathrm{O}_{2}$, low $\mathrm{CO}_{2}$, and high pulmonary blood flow are established.

The stimulus to increased prostacyclin synthesis cannot be elucidated from the current experiments. Obvious candidates are rhythmic gaseous ventilation and tissue distortion, increased intrapulmonary oxygen, decreased intrapulmonary carbon dioxide with consequent increased $\mathrm{pH}$. Reduced $\mathrm{PCO}_{2}$ and consequent elevated $\mathrm{pH}$ seem to be unlikely candidates as spontaneously ventilating neonatal ( $15 \mathrm{~min}$ after birth) $\mathrm{PaCO}_{2}$ tends to be higher rather than lower than in the fetus. However, it is possible that intrapulmonary $\mathrm{PCO}_{2}$ near sites of prostacyclin synthesis is reduced following ventilation even though arterial $\mathrm{PCO}_{2}$ is elevated. It is unlikely that the elevated $\mathrm{PCO}_{2}$ and consequent decreased $\mathrm{pH}$ that occurred $15 \mathrm{~min}$ after spontaneous onset of ventilation was the stimulus for increased prostacyclin synthesis since similar increases in prostacyclin production were observed in mechanically ventilated fetuses where $\mathrm{PCO}_{2}$ decreased immediately upon initiation of ventilation $(15,17)$. Elevated $\mathrm{PO}_{2}$ also is an unlikely candidate for the stimulation of prostacyclin synthesis by the lung at birth since hypoxia stimulated pulmonary prostacyclin synthesis in neonatal (9) and adult (29) lungs. In adult animals, mechanical stimuli including hyperinflation and hyperventilation stimulate pulmonary prostacyclin synthesis (25). Therefore, the tissue distortion of rhythmic gaseous ventilation seems to be the most likely component of ventilation at birth to be responsible for induction of pulmonary prostacyclin synthesis. Additionally, prostacyclin synthesis could be stimulated by other possible mediators, e.g. bradykinin $(11,26)$.

An important role of prostacylin in perinatal pulmonary vascular transition would have clinical significance. Prostaglandin cyclooxygenase inhibitors may be used to postpone labor (30, $31)$ or to accomplish pharmacological closure of a patent ductus arteriosus in the neonate $(6,12)$. Many pregnant women continue to use aspirin-containing drugs as analgesics, antipyretics, and anti-inflammatory agents. It has been reported by others that indomethacin may interfere with normal circulatory adjustments at birth in man (22), as we would predict could be possible from our experiments on goats and sheep. Obviously, many women ingest nonsteroidal anti-inflammatory agents and deliver healthy, normal babies. Nevertheless, an association between maternal nonsteroidal anti-inflammatory agent treatment and persistent pulmonary hypertension of the newborn has been observed $(19,23)$. Since the decrease in pulmonary vascular resistance at the time of birth is an event upon which the future existence of the organism depends, it would be surprising if a single mechanism were solely responsible. Rather, several mechanisms and mediators probably are involved. It is possible that factors such as pre- or intrapartum asphyxia, acidemia, or neonatal alveolar hypoxia and hypercapnia compromise other mediators and, thereby, accentuate the importance of the prostanoid system. As usually is true of maternal consumption of prostaglandin synthesis inhibitors, neonatal treatment with prostaglan- 
din cyclooxygenase inhibitors to close a patent ductus arteriosus does not result in progressive pulmonary hypertension. However, the clinical syndrome of symptomatic patent ductus arteriosus is characterized by left to right shunting through the patent ductus arteriosus as a result of low pulmonary vascular resistance. The lung and pulmonary vasculature are oxygenated well and normocapnic. The data presented in the current report suggest that the importance of prostacyclin is diminished greatly shortly after birth with appropriate pulmonary vascular transition and, thus, one would not expect progressive pulmonary hypertension to develop from neonatal prostanoid synthesis inhibition for treatment of a patent ductus arteriosus.

A role of prostacyclin in pulmonary vasodilation at birth is not the only possible explanation for the predisposition of babies delivered from mothers treated with nonsteroidal anti-inflammatory drugs toward persistent fetal circulation. Another hypothesis is that prolonged pulmonary hypertension resulting from in utero ductal closure increases development of precapillary resistance vessels in the lung $(19,20)$. These two effects of perinatal prostaglandin cyclooxygenase inhibition (i.e. reduction of vasodilatory prostacyclin and pulmonary vascular smooth muscle hypertrophy) could act synergistically to increase pulmonary vascular resistance and reactivity to pressor stimuli.

Noticeably, plasma prostacyclin levels in the fetus and neonate are considerably higher than have been reported in antecubital venous plasma from human adults (1). Previously, we have reported that, using identical methods to those used in the present study, fetal pulmonary arterial prostacyclin concentrations are more than four times higher than those of the ewe (18); and pregnant animals have elevated plasma prostacyclin when compared to nonpregnant $(7,21)$. Late pregnant human venous plasma 6-keto-PGF ${ }_{1 \alpha}$ concentration $(244 \mathrm{pg} / \mathrm{ml})$ determined by gas chromatography-mass spectrometry (21) is similar to the concentration we obtained from arterial plasma of near term pregnant ewes $(105 \mathrm{pg} / \mathrm{ml}$ of blood $=175 \mathrm{pg} / \mathrm{ml}$ plasma when hematocrit $=40 \%)(18)$.

In conclusion, the data presented in this report and our previous investigations utilizing various exteriorized fetal preparations are consistent with the hypothesis that the onset of ventilation at birth stimulates intrapulmonary synthesis of prostacyclin leading to high local concentrations near sites of production, thereby decreasing pulmonary vascular smooth muscle tone. Intrapulmonary synthesis of prostacyclin is one component of pulmonary vasodilation at birth. However, mechanisms unrelated to prostanoids certainly are important.

Acknowledgments. We acknowledge the excellent technical assistance of Randy Jerkins, Tamera Bateman, Mildred Jackson, and Patti Jessup.

\section{REFERENCES}

1. Blair IA, Barron SE, Waddell KA, Lewis PJ, Dollery CT 1982 Prostacyclin is not a circulating hormone in man. Prostaglandins 23:579

2. Brown BW, Hollander M 1977 Statistics: A Biomedical Introduction. John Wiley and Sons, New York

3. Cassin S 1982 Humoral factors affecting pulmonary blood flow in the fetus and newborn infant. In: Packham GJ, Heymann MA (eds) Cardiovascular Sequelae of Asphykia in the Newborn, Report of the Eighty-Third Ross
Conference on Pediatric Research, pp 10-18. Ross Laboratories, Columbus, $\mathrm{OH}$

4. Cassin S, Dawes GS, Mott JC, Ross BB, Strang LB 1964 The vascular resistance of the fetal and newly ventilated lung of the lamb. J Physiol (Lond) 171:61

5. Cassin S, Winikor I, Tod M, Philips J, Frisinger J, Jordan J, Gibbs C 1981 Effects of prostacyclin on the fetal pulmonary circulation. Pediatr Pharmacol 1:197

6. Friedman WF, Herschklau MJ, Printz MP, Pitlick PT, Kirkpatrick SE 1976 Pharmacologic closure of patent ductus arteriosus in the preterm infant. $\mathrm{N}$ Engl J Med 295:526

7. Gerber JG, Payne NA, Murphy RC, Nies AS 1981 Prostacyclin produced by the pregnant uterus in the dog may act as a circulating vasodepressor substance. J Clin Invest 67:632

8. Glantz SA 1981 Primer of Biostatistics. McGraw-Hill, New York

9. Green R, Leffler CW 1982 Neonatal pulmonary vascular prostaglandin production during hypoxia. Clin Res 30:910A (abstr)

10. Green R, Rojas J, Sundell H 1979 Pulmonary vascular responses to prostacyclin in fetal lambs. Prostaglandins 18:927

11. Heymann HA, Rudolph AM, Nies AS, Melmon KL 1969 Bradykinin production associated with oxygenation of the fetal lamb. Circ Res 25:521

12. Heymann MA, Rudolph AM, Silverman NH 1976 Closure of the ductus arteriosus in premature infants by inhibition of prostaglandin synthesis. $\mathrm{N}$ Engl J Med 295:530

13. Leffler CW, Tyler TL, Cassin S 1978 Effect of indomethacin on pulmonary vascular response to ventilation of fetal goats. Am J Physiol 234:H346 (Heart Circ Physiol 3)

14. Leffler CW, Hessler JR 1979 Pulmonary and systemic vascular effects of exogenous prostaglandin $\mathrm{I}_{2}$ in fetal lambs. Eur J Pharmacol 54:37

15. Leffler CW, Hessler JR, Terragno, NA 1980 Ventilation-induced release of prostaglandinlike material from fetal lungs. Am J Physiol 238:H282 (Heart Circ Physiol 7)

16. Leffler CW, Desiderio DM, Wakelyn CE 1981 Preparation of biological fluids for simultaneous analysis of prostaglandin cyclo-oxygenase synthesized compounds by gas-chromatography with electron capture detection. Prostaglandins $21: 227$

17. Leffler CW, Hessler JR 1981 Perinatal pulmonary prostaglandin production. Am J Physiol 241:H756 (Heart Circ Physiol 10)

18. Leffler CW, Hessler JR, Green RS 1982 Surgery increases fetal plasma prostacylin. Prostaglandins 24:387

19. Levin DL, Fixler DE, Morriss FC, Tyson J 1978 Morphologic analysis of the pulmonary vascular bed in infants exposed in utero to prostaglandin synthetase inhibitors. J Pediatr 92:478

20. Levin DL, Mills LJ, Parkey M, Garriott J, Campbell W 1979 Constriction of the fetal ductus arteriosus after administration of indomethacin to the pregnant ewe. J Pediatr 94:647

21. Lewis PJ, Boylan P, Friedman LA, Hensby CN, Downing I 1980 Prostacyclin in pregnancy. Br Med 280:1581

22. Manchester D, Margolis HS, Sheldon RE 1976 Possible association between maternal indomethacin therapy and primary pulmonary hypertension of the newborn. Am J Obstet Gynecol 126:467

23. Perkin RM, Levin DL, Clark R 1980 Serum salicylate levels and right-to-left ductus shunts in newborn infants with persistent pulmonary hypertension. J Pediatr 96:721

24. Powell WS 1980 Rapid extraction of oxygenated metabolites of arachidonic acid from biological samples using octadecylsilyl silica. Prostaglandins 20:947

25. Said SI 1982 Pulmonary metabolism of prostaglandins and vasoactive peptides. Annu Rev Physiol 44:257

26. Stalcup SA, Davidson D, Mellins RB 1982 Pulmonary metabolism of vasoactive substances in normal and asphyxiated births. In: Peckham GJ, Heymann MA (eds) Cardiovascular Sequelae of Asphyxia in the Newborn, Report of the Eighty-third Ross Conference on Pediatric Research, pp 44-51. Ross Laboratories, Columbus, $\mathrm{OH}$

27. Stanek KA, Coleman TG, Murphy WR, Smith TL 1981 Chronic arterial catheters in the rat. Fed Proc 40:525 (abstr)

28. Tyler T, Wallis R, Leffler C, Cassin S 1975 The effects of indomethacin on the pulmonary vascular response to hypoxia in the premature and mature newborn goat. Proc Soc Exp Biol Med 150:695

29. Voelkel WF, Gerber JG, McMurtry IF, Nies AS, Reeves JT 1981 Release of vasodilator prostaglandin, $\mathrm{PGI}_{2}$, from isolated rat lung during vasoconstriction. Circ Res 48:207

30. Wiqvist N, Lunstrome V, Green K 1975 Premature labour and indomethacin. Prostaglandins 10:515

31. Zuckerman H, Reiss U, Rubinstein I 1974 Inhibition of human premature labor by indomethacin. Obstet Gynecol 44:787 